\title{
The Role of Regional Capability in Understanding Regional Inequality: A Case Study of Indonesia
}

\author{
Pratiwi Ngasaratun \\ Universitas Gajah Mada \\ pngasaratun@gmail.com
}

\begin{abstract}
This paper aims to review some approaches in addressing inequality by considering the changes in the discourse of inequality with regard to development. It is examining income inequality as it becomes the main comcern in the beginning of the development theory. In the discussion of the pro-poor growth approaches, it recognize that despite income inequality, there were poverty and economic growth that need to be addressed in order to achieve development objectives. It is noticed in the inclusive growth approaches that income or wealth alone is not sufficient to explain the persistence of inequality for other aspects of welfare, therefore capability is believed as the appropriate instrument in achieving human well-beingness. As a case study, Indonesia has experienced inequality that is increasing during the last decades. The causes of inequality in Indonesia are complex and multi-dimensions. There is also a significant evidence of an increase in inequality of opportunity in Indonesia. Various indicators, such as education, health, and employment show a widening gap for people in Indonesia in accessing it. Therefore, stakeholders has to formulate proper policies to ensure a more prosperous and equal future for all Indonesians.
\end{abstract}

\section{Introduction}

The paper aims to review some literatures in the school of thought of inequality and capability. There has been long and deep discussion of inequality in the development discourse and policy due to its importance for human well-being. As Therborn (2013) stated that "inequality is a violation of human dignity", some empirical investigations found that problem occurs caused by this particular circumstances were various. Firstly, high inequality may hampers poverty alleviation, undermine stability particularly in terms of political and social stability due to the conflicts and tensions because social stratification. Second, in the last century, international inequality is declined due to the globalization impact. The widespread of technology, global trade, and transnational mobilty of labor as well as capital account for the decreasing of global inequality (Borguignon in Khondker, 2017). Paradoxically, globalization also become the reason of the widening gap within countries. The low wage transfer for the low-skilled labour to the Global South has responsible in causing the working classes in the North poorer (Borguignon in Khondker, 2017). Lastly, Stewart (2016) implied that reducing inequality is very important for the sake of inequality itself. High inequality is incompatible with a fair society, therefore preventing people for experiencing inequality is significantly needed for the justice. Moreover, equal circumstances also instrumentally viewed as influenscing the development objectives such as economic growth, stability, and poverty reduction.

Given these serious problems as the impact of high inequality, huge literatures from both theoritical and empirical research put concerns in this particular topic. This paper considers 
the changes in the discourse of inequality with regard to development, emphasizing in alternative approach based on capability theory in order to understanding inequality. The rest of the paper is arranged as follows. The next section will discuss inequality in early development approach. Section 3 reviews the pro-poor approach in addressing inequality. Following is the discussion on reducing inequality through theinclusive growth approach. The next section will examine the capability approach as an alternative in understanding inequality. A case study of Indonesia will be reviewed. The last section is concluding remarks.

\section{Early Development Approach}

In the beginning of the development theory, the prime concern in examining inequality has been income inequality since income was the best indicator for prosperity. Income inequality usually investigated in the context of a long-term growth especially for developing countries. Kuznet (1955) provided patterns of inequality as a framework in figuring out inequality. He stated that in the early stage of development, the growth rate and income distribution involved a trade-off which shown by the inverted U-curve hypothesis (Kuznet, 1955). The hypothesis was developed based on two primary assumptions. Fristly, a significantly divided income distribution among urban industry and rural agriculture, and secondly, there were less inter-sectoral inequality within rural agriculture than that of in urban industry. It is caused by the migration of workers from agriculture sector into the industrial sector that revealing the weight addition on the sector with greater inequality risen while the gap between the two sectors also incrase. The consequence is that at the first stage of development, overall inequality widen and then stabilize for some time before falling (Kuznet, 1955).

With regards to the inequality theory of Kuznet, the policy implication on development taken by the policy makers concerned on economic growth, and attention on income distribution were sidelined. Other studies also showed that more saving propensity was possessed by the capitalist rather than the employers and so that the impact of inequality tended to be good rather than bad to economic growth (Goodwin, 1967).

Following these concerns, empirical research on inequality and development were conducted by scholars to address two main questions: what is the impact of economic growth on the inequality, and what is the impact of inequality on growth. Some studies found that rapid growth was accompanied with decreasing inequality, while other studies asserted that inequality also rose during periods of depression and stagnation (Ravallion and Chen, 1997; Dollar and Kraay, 2002, Kanbur, 2011). With regards to the second question, several studies showed that high disparity could increase the effect of both market and capital failures on economic growth (Perotti, 1996; Alessina and Rodrik, 1994), while Lopez (2004) founds no relation among inequality and growth. However, as time went by, more researchers viewed that equity and possessing more asset could exacerbate growth. In the next development studies, as the global poverty increased into the endanger level, focus were shifted into personal income distribution of the people in the lowest level on the distribution link. 


\section{Pro-Poor Growth Approach}

In the discussion of the pro-poor growth appraoches, there were three development goals that became the main attentions: economic growth, inequality, and poverty alleviation which were different yet connected. The objective was emphasized on the last focus by fostering growth and lower inequality. It was believed that rapid economic growth would lead to improvements on all sectors while lower inequality asserted advancement of the poor (Ravallion, 2004). There was two arguments lied regarding to this particular approach. Firstly, those who believed that reducing poverty through economic growth would gain success as long as the poor enjoyed risen per capita income (Ravallion, 2004). Thus, economic growth categorized as pro-poor even the inequality increased since poverty declined. Second, some studies implied that economic growth was regarded to be pro-poor if the incomes of the poor increased faster that those of the noon-poor, then, as an impact there would be inequality reduction (Kakwani et al., 2004).

These debates led to the different instrument established by policy makers in order to reducing pocerty effectively. On the one hand, rapid economic growth would improve in all aspects of human welfare while on the other hand, less inequality would increase the wealth of the poor. McKinley (2010) asserted that reducing poverty could be done by (1) reducing inequality without considering economic growth (2) fostering growth without regarding to reduce inequality; or (3) combining faster growth as well as increasing equity.

However, as noted in the earlier part on this paper that both growth and inequality were linked each other, so any policy established in order to reduce poverty that influenced growth, can also influenced inequality. Hence, discussion on pro-poor growth were stalled as these choices was viewed as too limiting (McKinley, 2010). Moreover, there was recognition that wealth and equity were decreasing in many developing countries, and largely, it affected those who categorized as non-poor population. Due to this condition, the concept of inclusive growth started to emerge in the development discourse.

\section{Inclusive Growth Approach}

The main idea of inclusive growth approach was to extend benefits of the development process to as many as people in the population. It emphasized on the view that economic growth must be come together with equity (Rauniyar and Kanbur, 2010). Moreover, Birdsall (2007) stated that inclusive growth refers to development that focused on the increasing in the proportion of both income and people of the middle-class of the society. Broadly speaking, inclusive growth approach refers to equity with growth or to broadly shared well-being resulting from economic growth.

As changes in inequality are related to changes in growth (or growth structure), it is important to ensure that growth is associated with a disproportionate rise in the incomes of those who has lower income in the distribution curve. Thus, it would be essential to identify policies that change the bias of growth distribution while improving (or maintaining) the long-term growth. Since inequality and growth are not bound in some irreversible relationship, other 
factors such as policies as well as external conditions can be more important in determining the range of results observed in the relationship between inequality and growth. Therefore, focus has to be put on the factors that affect the shared evolution of equality and growth rather than on the rate of growth solely.

There are two important policy implications with regard to this particular framework involving inequality, growth and poverty. First, it is necessary to ensure that policies taken to address inequality can also promote economic growth that will improve welfare. Due to inequality and growth connected and also influenced by other conditions, it is important to pay attention not only to economic growth but also to equality. Secondly, as Rauniyar and Kanbur (2010) state that if poverty reduction policies become development goals, the focus should also be placed on the poorest economic growth. By increasing their growth rate, it is believed that poverty will decrease in one level while at the same time reducing the disparity between groups. To conclude, the inequality of income and wealth is important for inequality in aspects of non-income welfare. But, as many have warned, it is a mistake to assume that income or wealth alone is sufficient to explain the persistence of inequality for other aspects of welfare (non-income).

\section{Capability Approach}

In the late 1970s, the attention of development discourse has shifted beyond the inequality of income. The work of Amartya Sen has been the pioneer in the discussion of inequalities in development (1979, 1992, 1997, 2003). According to Sen, the extraordinary concerns about income and economic growth as a development goal confuse the means and goals of development. Sen argues that the ultimate goal of development is to improve the quality of lives and well-beingness of the people rather than achieving high income. As Sen stated that "The problem of concentrating on inequality of incomes as the primary focus of attention is that the extent of real inequality of opportunities that people face cannot be deduced from the magnitude of inequality of incomes, since what we can or cannot do, can or cannot achieve, do not depend just on our incomes but also on a variety of physical and social characteristics that affect our lives and make us what we are" (Sen, 1992:28).

The idea of prosperity was captured by the concept of capability. This term refers not only to what people can do, but also their freedom to choose the kind of life they value or have reason to be valued. In short, capability is the capacity and freedom to choose and act (Sen, 1997). However, there were serius discussion in determining capability approach given its complexity. As it might be noticed that what people value to do or to become are greatly various. In addition, determining what constitutes the capability set should be related to the underlying social issues and values, since the context decides which functions and abilities may be important and others insignificant or meaningless. Thus, the set of functions and abilities can include basic functions such as escaping morbidity and mortality and being given adequate nutrition for more complex functions such as achieving self-esteem and taking part in people's lives (Nussbaum and Sen 1993, Nussbaum 2000). 
The capability approach's main idea is on the freedom to choose one kind of life rather than another-not on incomes, especially as the relation between income, on the one hand, and individual achievements and freedom, on the other, appeared to be highly variably and dependent on contingent circumstances (Sen, 1971:70). These circumstances included: personal heterogeneities, environmental diversities, differences in relational perspectives, and distribution within the family. All of these circumstances, according to Sen, can help to explain the variability between incomes and other substantive achievements such as being healthy, being well-nourished, participating in the life of the community and so on. Furthermore, since people's abilities to activate these primary goods varied, the importance of looking into "the actual living that people manage to achieve" was emphasized. Put differently, the emphasis was on securing a real opportunity for every individual to achieve the functionings that he or she desired. Sen thus answers the question of inequality of what by advocating his preferred notion of equality, which is based on the capability for functionings.

The contribution of the human capability approach to the development discourse on inequality was and remains hugely influential. By arguing that equal incomes may not translate into a more equitable level of human capabilities, it emphasized that the opportunities that gave individuals the freedom to pursue a life of their own choosing needed to be equalized. However, outcomes and opportunities are clearly closely related. Both are mutually reinforcing, with unequal opportunities leading to unequal outcomes, and outcomes affecting opportunities for both current and future generations. Giving equal opportunities is not possible to improve the well-being of disadvantaged groups if income inequality increases at the same time. When rich children can go to college without collecting huge debts or having access to quality health care, it is difficult to say that income is not a problem for opportunities to move forward in life. The assumption that fair results can come from an unfair starting point that can be replicated. But inequality in opportunities is also important for three reasons: First, they can magnify the distribution consequences of the factors that drive income inequality. For example, inequality in education is a major contributor to income inequality and the same applies to health. Second, without equal opportunities, it will be difficult to overcome horizontal or vertical inequalities. Third, equal opportunity has intrinsic value. Thus, responsible policymakers will ensure that human welfare must address inequalities at all dimensions that are important to welfare, focusing primarily on households and groups that remain so consistent on the margins of economic, social and political life.

\section{Case Selection: Indonesia}

During the last decades, Indonesia has experienced increasing in income inequality. As shown by the figure 1, higher growth seems to have negative consequence on income distribution as shown by the Gini index, which increased sharply. The income gap between those at the bottom decile and those at the top widened as shown by the Gini index, which reached 0.41 in 2014. The 10 percentage point increase in the Gini index over 10 years was considered high among other developing countries. It is also the highest increase for a country in South Asia. 
Figure 1: Poverty, Inequality, and GDP per Capita in Indonesia

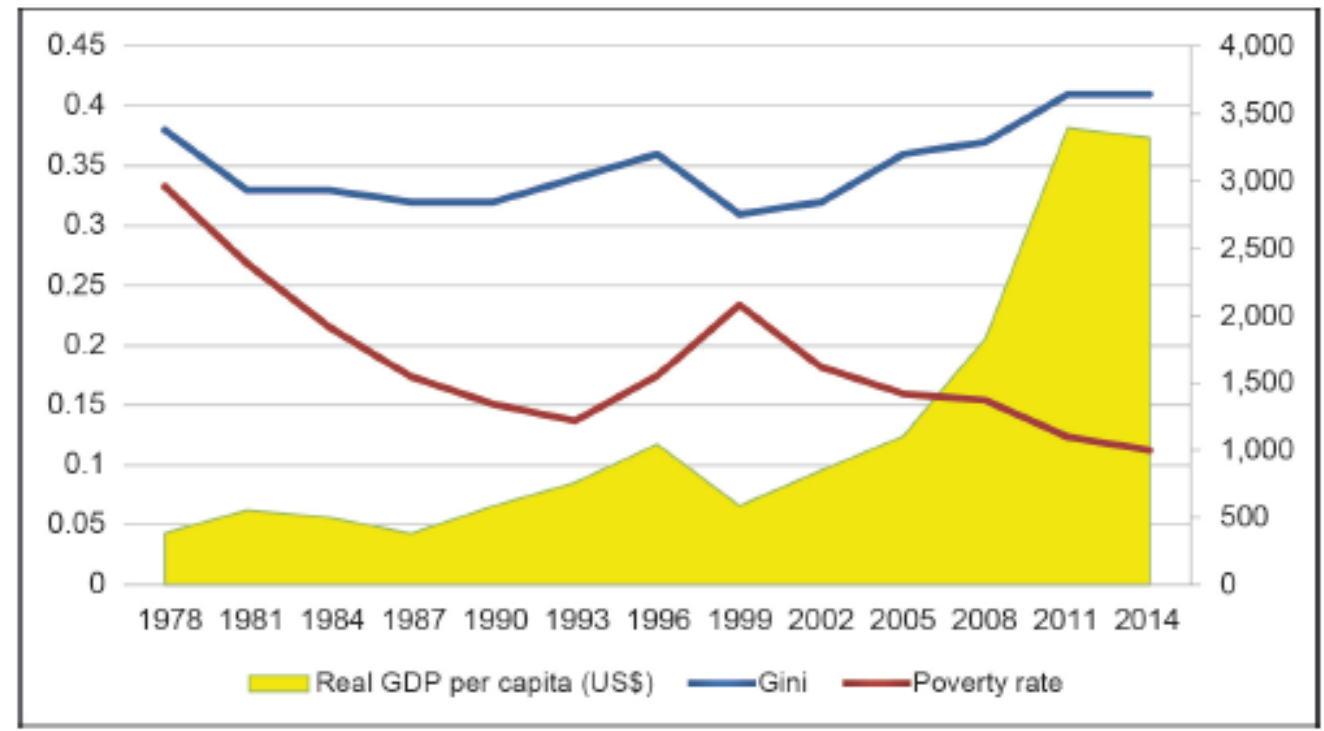

GDP $=$ gross domestic product.

Source: Indonesia Central Statistics Agency, the World Bank.

INFID (2017) reported that urban inequality has been growing, causing higher risk of the impact of inequality in the future since Indonesia also known as the highest urbanization country in Asia. Surely, the widening inequality has to be considered seriously as it is threatening Indonesia's well-beingness. If inequality is not addressed properly, alleviating poverty will take extra effort, social instability could rise, and moreover economic growth could be hampered (Stiglitz, 2016). Therefore, serious actions to address inequality could lift millions of people into well-beingness, lead to a more cohesive society, foster equitable and sustainable growth, and help Indonesia to meet its national goals.

The causes of inequality in Indonesia are complex and multi-dimensions Several factors contributed to the increase in income inequality during the $2000 \mathrm{~s}$. The first factor is the commodity boom, particularly the rise in prices of coal and palm oil (Burke and Resosudarmo, 2012). Yusuf (2014) asserted that changes in inequality are due to rising world prices of mining commodities rather than plantation crops such as palm oil, coffee, coconut and cocoa. Accordingly, Suryahadi et al. (2009) notes that changes in sectoral contributions to growth are associated with a slowing poverty alleviation, which reveals the potential for changes in inequality.

Secondly, inequality is related to changes in the labor market. Yusuf et al., (2013) stated that the rigidity of the labor market in the formal labor market including interrelated changes in labor market regulations, such as increased severance pay, union strengthening, minimum wage increases, reduced demand for unskilled labor work, and increased informality in lowpaid jobs. Historically, job opportunities in the formal manufacturing sector have become shelter for people in rural areas looking for better paying jobs. Thus, when such opportunities are limited, there is an excess supply of unskilled labor in rural areas. As labor markets in rural areas are flexible, overall rural real wages are suppressed for unskilled workers, causing increasing inequality in rural areas. Official data from Statistics Indonesia show that real 
wages for agricultural workers have declined over the past few years, due to fewer manufacturing activities, leading to a lack of formal employment in cities (Manning and Pratomo, 2013).

The third inequality driver is the price of rice. Between 2003 and 2005, the domestic price of rice increased by almost 20 per cent after having been very stable for years. This spike may have forced households to spend a larger share of their income on rice, and thus reduced the real expenditure on other items, particularly among the poor.

The fourth driver of changes in inequality is regressive government expenditure. From 2003 to 2005, world oil prices rose by 70 per cent, leading to an increase of fuel subsidies from 6.5 per cent of the total state budget (Anggaran Pendapatan Belanja Negara, APBN) in 2003 to almost 16 per cent in 2005. This increased responsibility and curtailed the fiscal space for additional government social spending on the poor, while the fuel subsidy disproportionately benefited the non-poor. A structural driver that could also have contributed to rising inequality, declining poverty reduction and slower economic growth is inequality of opportunity. As the key to economic prosperity, access to betterpaying or formal jobs is associated with access to better education and good health.

Previous studies on inequality in Indonesia have focused on income inequality (Asra, 2000; Tadjoeddin, 2016) which is mirroring the early development approach. In the next development, recently, the government combines pro-growth development policy with a propoor and pro-jobs orientation (Tadjoeddin, 2016). This particular approach echoes The World Bank (2008:6) which determines quality of growth in terms of 'aspects of growth that especially reduce extreme poverty, narrow structural inequalities, protect the environment, and sustain the growth process itself'. Tadjoeddin (2016) examines employees' real earning, income inequality and productivity in Indonesia, he finds out that there was disconnection between productivity and employees' salary causing the unequal distribution of income.

With regards to the capability approach, ESCAP (2017) in its working paper reported that between 2000-2015, there is a significant evidence of an increase in inequality of opportunity in Indonesia. Various indicators, such as education, health, and employment show a widening gap for people in Indonesia in accessing it. Interregional gaps both within and outside Java; and rural-urban differences are still large and have persisted over time while there is also unequal access to water and sanitation between income groups. In the area of employment, ESCAP finds that the degree of formality in the Indonesian labour market, even for the country's average, has not been improving for the last 15 years. Informality also remains concentrated in non-Java and rural areas as well as within the 40 per cent poorest population. Inequality of opportunity in terms of access to better employment has been one of the hardest dimensions to tackle for contemporary Indonesian development.

In terms of education, good quality education is available in Indonesia, but it cannot be accessed by everyone. Basic elementary education has been universally available and accessible.. There is also no significant difference between males and females in primary school enrollment rate. It is strongly accepted that this equal condition is the result of 
compulsory primary education policy that has been delivered since the 1980 s. The success of the compulsory primary education programme is also proven by the minimal difference between the net primary enrollment of children from the top 10 per cent and bottom 40 per cent. However, the job market takes into account mostly for the secondary or tertiary level of education. In addressing this trend, the govenment then started to promote junior secondary compulsory education. As a result, the average net secondary enrollment (both junior, i.e., 13-15 years of age, and senior i.e., 16-18 years of age) steadily increased to almost 80 per cent in 2015, compared to 60 per cent in 2000. In general, there is no significant difference between male and female in net secondary enrollment.

Thus, almost all indicators related to education experienced improvement for the average population over the period of 2000-2015, with inequality in education also falling in general. Between Java and non-Java regions, the education o especially utcomes have been relatively equal. Between urban and rural areas, the outcomes have been markedly unequal. For some indicators, the urban-rural gap has been narrowing especially in secondary net enrollment rate and literacy rate. Some indicators still show a gender gap to some extent, for instance in years of schooling and the literacy rate. The most serious gap is that of education outcomes between income groups, in this case between the top 10 per cent and the bottom 40 per cent. Inequality between these groups appears quite significant and in one particular case, the mean years of schooling, the gap has been widening for the last 15 years.

In the health sector, inequalities in access to health services are evident and are persisting over time. Progress in tackling inequalities sector has been less satisfying than that of in the education sector. Certain indicators show slow or limited improvement (malnutrition, stunting, wasting) even for the average population. There are some overall improvements in infrastructure and services such as access to water and sanitation, number of physicians, and births being assisted by health workers. Among the most notable are inequalities between Java and non-Java regions, in almost all health indicators, particularly in access to health care during birth. Improved sanitation access is still highly unequal between urban and rural areas and does not show any sign of improving. Access to water and sanitation between the top 10 per cent to the bottom 40 per cent is also very unequal.

In terms of employment, indicators shown that inequalities remain persistent between regions (both between Java and non-Java and urban-rural areas) and between income groups (bottom 40 per cent and the top 10 per cent). The Indonesian labour market is characterized by high informality, which has hardly moved over the last 15 years. There is a very strong association between having a formal job and belonging to the top 10 per cent, which has also been increasing over the past 15 years. Gender stereotypes seem to keep women in vulnerable jobs, or outside of the labour market altogether. Overall, it is clear that inequalities in access to better employment opportunities are one of the most serious challenges for contemporary Indonesian development. 


\section{Concluding Remarks}

There is growing awareness in the development discourse that focusing in income inequality alone is not sufficient in understanding and overcoming human inequality. Capability emerged as an alternative way to complement previous approaches in addressing inequality. Hence, In order to yield comprehensive policies, it needs to consider both income inequality as well as capability approaches. With political will and the right policy decisions, the government can turn the tide on extreme inequality and ensure a more prosperous and equal future for all Indonesians.

\section{References}

Alesina, A. and D. Rodrik (1994). "Distributive Politics and Economic Growth", The Quarterly Journal of Economics, Vol. 109, No. 2, pp. 465-490.

Asra, A., (2000) Poverty and Inequality in Indonesia: Estimates, decomposition, and key issues. Journal of the Asia Pacific Economy (1):2 pp: 91-111

Birdsall, N. (2007). "Reflections on the Macro Foundations of the Middle Class in the Developing World", Working Paper Number 130. Washington, DC: Center for Global Development.

Khondker, H.H., (2017). Globalization and inequality. International Sociology Reviews Vol. 32(2) $170-179$

Burke, Paul J., and Budy P. Resosudarmo (2012). "Survey of recent developments." Bulletin of Indonesian Economic Studies 48.3: 299-324.Dollar and Kraay, 2002

Goodwin, R. (1967). "A Growth Cycle”, in Socialism, Capitalism and Economic Growth, C. H. Feinstein (ed.). Cambridge: Cambridge University Press.

OXFAM (2017). Towards More Equal Indonesia. Briefing Paper. February 2017

Kakwani, N., S. Khander and H. S. Son (2004). "Pro-Poor Growth: Concept and Measurement with Country Case Studies", Working Paper No 1, International Policy Center. Brasilia: United Nations Development Programme.

Kanbur, R. (2011). “Does Kuznets Still Matter?” Mimeo. Ithaca, NY: Cornell University.

Kuznets, S. (1955). "Economic Growth and Income inequality", The American Economic Review, Vol. 45, No. 1, pp. 1-28.

Lopez, J. H. (2004). "Pro-growth, pro-poor: Is there a trade-off?", Policy Research Working Paper 3378. Washington, DC: World Bank. 
Manning, Chris, and Devanto S. Pratomo (2013). "Do migrants get stuck in the informal sector? Findings from a household survey in four Indonesian cities." Bulletin of Indonesian Economic Studies 49.2:167-192.

McKinley, T. (2009). "Revisiting the dynamics of growth, inequality and poverty reduction", Discussion paper 25/09, Center for Development Policy and Research, School of Oriental and African Studies, University of London.

Nussbaum, M. (2000). Women and Human Development: The Capabilities Approach. Cambridge, UK: Cambridge University Press.

Nussbaum, M. and Amartya Sen (eds.) (1993). The Quality of Life. Oxford, UK: Clarendon Press.

Perrotti, R. (1996). "Growth, income distribution, and democracy: What the data say", Journal of Economic Growth, Vol. 1, No. 2, pp. 149-187.

Rauniyar, G. and R. Kanbur (2010). "Inclusive Development: Two Papers on Conceptualization, Application and the ADB Perspective", Journal of the Asia Pacific Economy, Vol. 15, No. 4, pp. 437-469.Ravallion and Chen, 1997

Ravallion, M. (2004). "Pro-poor growth: A primer", Policy Research Working Paper Series 3242. Washington, DC: World Bank.

Sen, A. (1979). "Equality of what?" The Tanner Lecture on Human Values, 22 May, Stanford University, Stanford, California.

Sen, A. (1992). Inequality Reexamined. New York: Oxford University Press.

Sen, A. (1997). "From Income Inequality to Economic Inequality", Southern Economic Journal, Vol. 64, No. 2, pp. 384-401.

Sen, A. (2003). "Development as Capability Expansion", in Readings in Human Development, Fukuda-Parr, S. Et al. (eds.). New Delhi and New York: Oxford University Press.

Stewart (2016) Changing Perspectives on Inequality and Development, St Comp Int Dev,Vol $51,60-80$

Stiglitz, J. E. (2016). Inequality and economic growth. In M. Jacobs and M. Mazzucato. Rethinking capitalism: economics and policy for sustainable and inclusive growth. pp. 134155. Oxford: John Wiley \& Sons

Suryahadi, Asep, Daniel Suryadarma, and Sudarno Sumarto (2009). "The effects of location and sectoral components of economic growth on poverty: Evidence from Indonesia." Journal of Development Economics 89.1: 109-117. 
Tadjoeddin, M.Z., (2016). Earnings, productivity and inequality in Indonesia. The Economic and Labour Relations Review 27:2 pp: $248-271$

Therborn, G. (2013). The Killing Fields of Inequality. Cambridge: Polity

World Bank (2008) The quality of growth: Fiscal policies for better results. IEG Working Paper 2008/6. Washington, DC: World Bank.

Yusuf, Arief Anshory (2014). "International Commodity Prices and Inequality in Indonesia." Working Papers in Economics and Development Studies (WoPEDS) No. 201409. Department of Economics, Padjadjaran University.

Yusuf, Arief, Komarulzaman, Ahmad, Purnagunawan, Raden and Resosudarmo, Budy, (2013). "Growth, Poverty and Labor Market Rigidity in Indonesia: A General Equilibrium Investigation." No 201304, Working Papers in Economics and Development Studies (WoPEDS), Department of Economics, Padjadjaran University. 